\title{
Work Stress and Outcome of Stress Among Malaysian Managers
}

\author{
Wong Shiet-Ching \\ Sunway University, Selangor, \\ Malaysia
}

\author{
Omar Fatimah \\ Universiti Kebangsaan Malaysia, \\ Bangi, Malaysia
}

\author{
Mahmud Malissa-Maria \\ Sunway University, Selangor, \\ Malaysia
}

\begin{abstract}
Work stress is always associated with managers' satisfaction, mental and physical well-being. Nevertheless, there are limited studies on causal relationship of stressors, satisfaction, organization and mental and physical well-being by using SEM (structural equation modeling) analysis among managers in Malaysia. The purpose of the present study is to ascertain the causal relationship of stress and the outcome of stress on managers' well-being. This was a cross sectional research, which consisted of 338 managers from various private sectors in Klang Valley and Kuala Lumpur, Malaysia. Pressure management indicator questionnaire was used as the measurement instrument in this study. The SEM results indicate that work stress has direct effect on satisfaction, mental and physical well-being. Meanwhile, satisfaction has direct effect on organization and mental well-being, organization has direct effect on mental well-being and mediators also have been identified in the study. The impact of work stress shows that mental well-being has greater effect on physical well-being compared to work stress.
\end{abstract}

Keywords: work stress, satisfaction, mental well-being, physical well-being

\section{Introduction}

Work stress incurred cost not only to the organization, but the nation as well. Western countries have well-documented the cost of stress. UK has lost 28.5 million days in 2010 (Health and Safety Executive, 2010), whereas in the European country, work stress has affected 22\% of the employee well-being (European Foundation for the Improvement of Living and Working Conditions, 2007). In the US, work stress has costs 300 billion in health care (Schwartz, 2004). In Selangor and Kuala Lumpur, Malaysia, there were 3,118 managers quitted their jobs (Ministry of Human Resources, 2009). However, there were 18,366 and 7,806 workers from Selangor and Kuala Lumpur registered with the Ministry of Human Resources, Malaysia, as new employees in the same year (Ministry of Human Resources, 2009). This may be caused by the work stress at their work places.

Work stress is influenced by perception of one (Folkman, Lazarus, Dunkel-Schtter, Delongis, \& Gruen, 1986). Hence, terms such as perceived job stress were used in stress study (Larsman, Thorn, Sogaard, Sandsjo, Sjogaard, \& Kadefors, 2009; Chiu, Chien, Lin, \& Hsiao, 2005; Leung, Siu, \& Spector, 2000; Spector, Cooper, \& Anguilar-Vafaie, 2002). Although individual perception has an impact on work stress, but, personality, long working hour and excessive workload have depicted negative effects on employees (Brett \& Stroh, 2003; Jamal \& Baba, 2003; Lu, Kao, Cooper, \& Spector, 2000). According to Sulsky and Smith (2005), stress is complicated, consisting of stimuli, cognitive appraisal, outcome of stress and moderator to alleviate the

Wong Shiet-Ching, Ph.D., American Degree Transfer Program, Sunway University. Omar Fatimah, Ph.D., Department of Psychology, Universiti Kebangsaan Malaysia. Mahmud Malissa-Maria, American Degree Transfer Program, Sunway University. 
outcome of stress. Work stress in this present study refers to the demands and challenges that caused unwanted outcome to the employee (Williams \& Cooper, 2002).

In addition to one's perception, work stress is always related with negative outcome, such as job satisfaction, organizational commitment and employees' well-being. Work stress is negatively associated with job satisfaction and organization commitment (Chiu et al., 2005). Managerial work is stress also reported negatively related with job satisfaction (Kirkcaldy, Trimpop, \& Williams, 2002) and organization (Lu, Tseng, \& Cooper, 1999). Work stress affects job satisfaction and organization, meanwhile it also has inversed relationship with manager's mental and physical well-being (Siu, Lu, \& Spector, 2007; Lu, Siu, \& Cooper, 2005; Kirkcaldy et al., 2002).

Job satisfaction and organizational commitment are focused on the emotional bond to the organization. According to Lee and Henderson (1996), job satisfaction and organizational commitment are attachment to the organization rather than to the job only. Locke (1976) defined that job satisfaction is the results from the perception that one's job fulfils and the values of the organization are synchronize with their values. High job satisfaction contributes to general well-being (D. Schultz \& S. E. Schultz, 2006), whereas low job satisfaction will lead to absenteeism and high turnover rate (Furnham, 2005). Kreitner and Kinicki (2008) believed that organizational commitment is the extent of an individual indentify with an organization and committed to its goal. The outcome of job satisfaction and organizational commitment are the same when the stress is excessive. Organizational commitment will decrease the turnover rate, absenteeism and vice versa (Meyer \& Herscovitch, 2001).

Mental well-being refers to the ability to live productively, the capacity to live to the fullest and ability to love and cooperate with others, adjusting to the world and being efficient (MacDonald, 2006). Physical well-being literally means one free from critical and chronic illness. Physical illness caused by work stress can be detected through one physiology reaction, such as headache, backache, high blood pressure, increase of heart palpitation and allergic (Stranks, 2005; Greenberg, 2004). Employees who are not able to cope with stress will experience physical strain (J. C. Quick \& J. D. Quick, 1984). High level of stress is related with low mental and physical well-being, whereas low level of stress is related with good mental and physical well-being (Siu et al., 2007; Spector et al., 2002; Siu, Cooper, \& Donald, 1997).

It is claimed that satisfaction and mental well-being is positively related with physical well-being (Siu, Spector, Cooper, Lu, \& Yu, 2002). In Kirkcaldy, Petersen and Hubner’s (2002) study, organizational security and organizational commitment are two of the subscales of satisfaction. The result depicted that satisfaction is positively related with physical well-being. In another words, organizational security and organizational commitment may be positively related with physical well-being. As a result, work stress is related with the outcome of stress and the outcome of stress is related to physical well-being. Therefore, the conceptual model of this study is stressor negatively associated with outcome of stress which is satisfaction, organization, mental and physical well-being. On the other hand, satisfaction, organization and mental well-being are positively related with physical well-being (see Figure 1).

The purpose of the present study is to investigate the causality and outcome of stress and the relationship of observed variables in the outcome of stress. There are limited studies of the causality of work stress and outcome of stress among the managers in Malaysia. Therefore, the present study is to examine the relationship of stress, satisfaction, organization and mental well-being on to physical well-being among the managers in Malaysia. This research is intent to improve the physical well-being of the managers in Malaysia generally. 


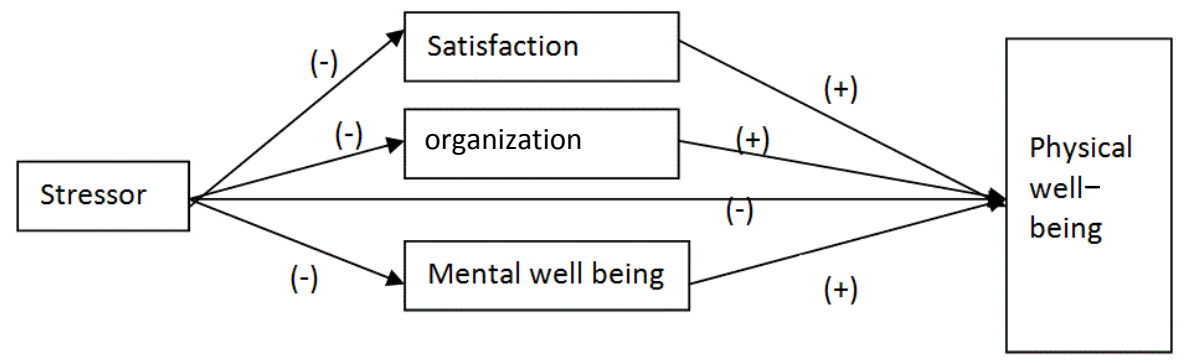

Figure 1. Conceptual model.

\section{Method}

\section{Subjects}

The data was gathered from 338 managers from Klang Valley and Kuala Lumpur, Malaysia. They are chosen, because both areas are the city and concentration of various industries. Managers participated in the present study were form various industries. There were 176 female (52\%) and 162 male (48\%), aged between 25 and 59 (mean = 33.72, standard deviation = 7.83), 72 Malay $(51 \%), 142$ Chinese $(42 \%)$ and 24 Indian $(7 \%)$.

\section{Measurement Tool}

The PMI (pressure management indicator) questionnaire was used in the present study (Williams, 2000). PMI is a compact and reliable stress measurement tool (Williams \& Cooper, 1998). PMI is a comprehensive measurement tool as well. It is a six-point Likert scale. Sources of stress encompass workload, relationship, recognition, organization climate, personal responsibility, managerial role, home/work balance and daily hassle. The higher scores mean higher stress one would experience. The outcome of stress is measured by satisfaction, organization, mental and physical well-being. Satisfaction is measured by job satisfaction and organizational satisfaction. Organization is measured by organizational security and organization commitment. Mental well-being is measured by the state of mind, resilience and confidence level, whereas physical well-being is measured by physical symptoms and energy level. Higher score mean higher satisfaction, organization and mental and physical well-being.

\section{Data Analysis}

SEM (structural equation modeling) was used in this present study because SEM was able to determine the casual relationship of the observed variable in single model. AMOS (analysis of moment structures software) was used to identify the measurement model of stressor, satisfaction and mental well-being. Modification index was used for repeated testing on the measurement model to verify the variables. After a few testing on the measurement model, few variables were removed from the measurement model. Goodness of fit indices, such as Chi-square, NFI (normed fit index), GFI (goodness-of-fit index), the RMSEA (root mean square error of approximation), the CFI (comparative fit index) and TLI (Tucker-Lewis index) were used to determine whether the model fit with the data collected.

\section{Result}

After several testing on the measurement model by using modification index, the goodness of fix indices for the measurement models is shown in Table 1.

The result depicted that the measurement models are fit with the data collected and met the requirement 
according to CFI, GFI and NFI, which is larger than 0.9 (Hu \& Bentler, 1999; Kline, 2005; Bentler, 1990), TLI larger than 0.95 (Hu \& Bentler, 1999) and RMSEA less than 0.08 (McDonald \& Ho, 2002).

Table 1

Goodness of Fit Indices for the Measurement Models

\begin{tabular}{lrrlllll}
\hline Measurement model & $\chi^{2}$ & $d f$ & NFI & GFI & RMSEA & CFI & TLI \\
\hline Sources of stress & 58.65 & 23 & 0.96 & 0.96 & 0.07 & 0.98 & 0.96 \\
Satisfaction & 28.00 & 9 & 0.96 & 0.97 & 0.08 & 0.98 & 0.97 \\
Organization & 19.99 & 9 & 0.931 & 0.98 & 0.00 & 0.96 & 1.0 \\
Mental well-being & 7.26 & 5 & 0.99 & 0.99 & 0.04 & 0.99 & 0.99 \\
Physical well-being & 11.05 & 5 & 0.98 & 0.99 & 0.06 & 0.99 & 0.98 \\
\hline
\end{tabular}

Notes. $\chi^{2}=$ Chi square; $d f=$ degree of freedom.

The overall model of stress, satisfaction, organization mental and physical well-being has the good fit with the data: $\chi^{2}=1.211, d f=2$, GFI $=0.99$, NFI $=0.99$, RMSEA $=0.00$, CFI $=1.00$, TLI $=1.01$, and $n=338$. Sources of stress has negative path coefficient with satisfaction $(-0.34, p<0.001)$, mental well-being $(-0.24, p<$ $0.001)$ and physical well-being $(-0.16, p<0.001)$. The result shows stress has negatively direct effect on satisfaction, mental and physical well-being, but stress does not have significantly direct effect on organization (see Figure 2).

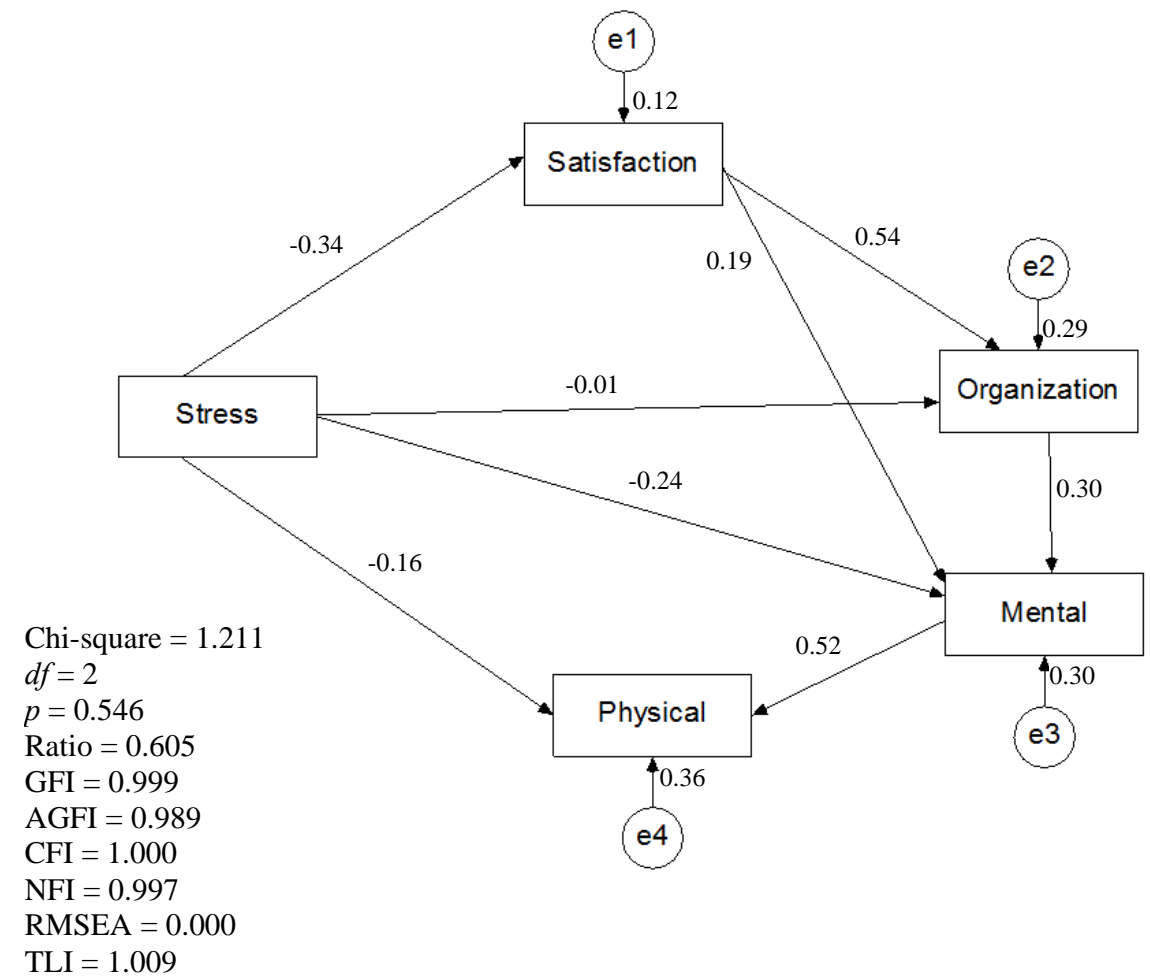

Figure 2. The standardized path coefficient and goodness of fit indices of stress, satisfaction, organization, mental and physical well-being model.

There are casual relationships between the outcomes of stress. Satisfaction has positive path coefficient with organization $(0.54, p<0.001)$ and mental well-being $(0.19, p<0.001)$, whereas organization has positive path coefficient with mental $(0.30, p<0.001)$, and mental has positive path coefficient with physical $(0.52, p<$ 
0.001). The result shows satisfaction and organization do not have direct effect on physical well-being, nevertheless satisfaction and organization have direct effect on mental well-being. In other words, satisfaction and organization through mental well-being affect physical well-being. Mental well-being is the main factor which affects physical well-being, even though stress can be another factor that affects physical well-being.

Stress has an indirect effect on organization through satisfaction, but stress is not related with organization significantly. According to Hair, Black, Babin, and Anderson (2010), the indirect effect is more than 0.08 and the value is sizable. Therefore, satisfaction is fully mediated stress and organization. Stress does not have an indirect effect neither through satisfaction nor organization to mental. Nevertheless, there is direct effect from stress to mental. Stress is significantly related with physical and has sizable value for indirect effect from stress through mental to physical (-0.12). Hence, mental is partially mediated stress and physical. Satisfaction is significantly related with mental and has sizable indirect effect from satisfaction through organization to mental (0.16). Hence, organization is partially mediated satisfaction and mental well-being (see Table 2).

Table 2

Analysis of Direct and Indirect Effect for the Variables of Stress, Satisfaction, Mental and Physical

\begin{tabular}{lll}
\hline Path variable & Indirect effect & Direct effect \\
\hline Stress $\rightarrow$ satisfaction $\rightarrow$ organization & -0.18 & -0.01 \\
Stress $\rightarrow$ organization $\rightarrow$ mental & 0.00 & -0.24 \\
Stress $\rightarrow$ satisfaction $\rightarrow$ mental & -0.06 & -0.24 \\
Stress $\rightarrow$ mental $\rightarrow$ physical & -0.12 & -0.16 \\
Satisfaction $\rightarrow$ organization $\rightarrow$ mental & 0.16 & 0.19 \\
\hline
\end{tabular}

\section{Discussion and Conclusions}

The purpose of the article is to examine the causal relationship of work stress and the relationship of the outcomes of stress on physical well-being. After analysis, the result showed that stress is negatively related with satisfaction, mental and physical well-being. This is consistent with the previous study (Siu, Spector, Cooper, \& Lu, 2005; Lu et al., 2000; Cooper, Kirkcaldy, \& Brown, 1994). Work stress will produce negative feeling towards job and reduce mental and physical functioning of managers.

This study revealed that work stress does not have direct an effect on organizational commitment and security, but it affects organization indirectly through job satisfaction, because satisfaction is fully mediate stress and organization. Managers who have excessive work stress will have low job satisfaction which in turn affects their commitment and feeling toward organization security.

Satisfaction is related to organization and mental well-being. As discussed above, satisfaction is the mediator for stress and organization, so it is not a surprise that satisfaction is related with organization. Managers who experience job satisfaction will have good mental well-being. The result is supported by previous study (Lu et al., 2005; Lu et al., 2000; Cooper et al., 1994). The result explains that job satisfaction will allow managers to have clearer state of mind and ability to cope with problems.

Organization is positively related with mental well-being. According to Storseth (2006), organizational commitment and mental well-being have bidirectional relation. Employee who has low organizational commitment will affect their mental well-being and vice versa. Furthermore, the result showed that mental well-being affects physical well-being positively. The result explained that managers with clear mind and confidence will have higher state of energy and better physical health. The result is supported by other 
researchers (Lu et al., 2005; Siu, 2002; Lu et al., 2000; Cooper et al., 1994).

Mental well-being is positively related with physical well-being, and the direct effect of mental well-being and physical well-being is greater than work stress and physical well-being. The result is corroborated with Siu (2002). In her study, the results indicated that mental well-being is related with physical well-being. Furthermore, mental and physical well-being has a stronger relation comparing work stress and physical well-being. Hence, mental well-being has stronger impact on physical well-being compared to work stress on physical well-being. This may due to perception and mindset that affect the mangers mental health. Perception and appraisal toward the environment affect an individual emotion (Lazarus, 1999). Hence, a stressful situation is perceived by one and it will affect his/her emotion and physical eventually.

The result indicated organization partially mediate satisfaction and mental well-being, and mental well-being also partially mediates stress and physical well-being. According to Baron and Kenny (1986), there are two types of mediator. There are fully mediated and partially mediated. Partially mediated is the independent variable and dependent variable is significant related, before or after adding the mediator in the relationship of independent and dependent variable. In other words, the relationship of independent variable and mediator is significant and stronger compared to the independent with the dependent variable. The result showed that the relation of satisfaction and organization is stronger than satisfaction and mental well-being, whereas the relation of stress and mental well-being is stronger than stress and physical well-being. This result is supported by the previous study (Siu, 2002). According to Kobasa, Maddi, and Kahn (1982), organizational commitment provides the sense of belonging which will enhance the positive outcome such as managers who will have better mental state.

There are two implications of the present study. Firstly, work stress has direct effect with satisfaction, mental and physical well-being, whereas mental well-being also has direct effect on physical well-being. Nevertheless, satisfaction and organization contribute to indirect effect on physical well-being. Therefore, higher management should be aware of the employees' work stress level, organizational commitment and their mental well-being, in order to reduce the cost of management. Employees who are not healthy may incur more cost in term of money, insurance and lost of working days. Furthermore, it may cause the organization to lose human asset. Secondly, organization is the mediator for satisfaction and mental well-being, mental well-being is the mediator for work stress and physical well-being, and satisfaction is the mediator for work stress and organization. By identifying the mediator, higher management is able to control the outcome of stress in a more effective way.

The present study is to examine the relationship of work stress and the outcome of stress among the managers. Hence, the future study should test the model on other occupational groups in order to be generalized to the population.

\section{References}

Baron, R. M., \& Kenny, D. A. (1986). The moderator-mediator variable distinction in social psychological research: Conceptual, strategic, and statistical considerations. Journal of Personality and Social Psychology, 51(6), 1173-1182.

Bentler, P. M. (1990). Comparative, fit indexes in structural models. Psychological Bulletin, 107(2), 238-246.

Brett, J. M., \& Stroh, L. K. (2003). Working 61 plus hours a week: Why do managers do it?. Journal of Applied Psychology, 88(1), 61-78.

Chiu, C. K., Chien, C. S., Lin, C. P., \& Hsiao, C. Y. (2005). Understanding hospital employee job stress and turnover intentions in a practical setting: The moderating role of locus of control. Journal of Management Development, 24(10), 837-855. 
Cooper, C. L., Kircaldy, B. D., \& Brown, J. (1994). A model of job stress and physical health: The role of individual differences. Person. Personality and Individual Differences, 16(4), 653-655.

European Foundation for the Improvement of Living and Working Conditions. (2007). Fourth European Working Conditions Survey. Retrieved from http://www.eurofound.europa.eu/publications/htmlfiles/ef0698.htm

Folkman, S., Lazarus, R. S., Dunkel-Schtter, C., Delongis, A., \& Gruen, R. (1986). Dynamics of a stressful Encounter: Cognitive Appraisal, Coping, and Encounter Outcomes. Journal of Personality and Social Psychology, 50(5), 992-1003.

Furnham, A. (2005). The psychology of behavioral at work: The individual in the organization (2nd ed.). New York: Psychology Press.

Greenberg, J. S. (2004). Comprehensive stress management (8th ed.). New York: McGrawHill.

Hair, J. F., Black, W. C., Babin, B. J., \& Anderson. (2010). Multivariate data analysis (7th ed.). New Jersey: Pearson Prentice Hall.

Health and Safety Executive. (2010). The health and safety executive statistics 2009/10. Retrieved from http://www. hse.gov.uk/statistics/overall/hssh0910.pdf

Hu, L. T., \& Bentler, P. M. (1999). Cutoff criteria for fit indexes in covariance structure analysis: Conventional criteria versus new alternatives. Structural Equation Modeling, 6(1), 1-55.

Jamal, M., \& Baba, V. V. (2003). Type A behavior, components, and outcomes: A study of Canadian employees. International of Stress Management, 10(1), 39-50.

Kirkcaldy, B. D., Petersen, L. E., \& Hubner, G. (2002a). Managing the stress of bringing the economy in the eastern German states to the level of the western German states: A comparison of occupational stress, physical and psychological well-being and coping managers from west and the former East German. European Psychologist, 7(1), 53-62.

Kirkcaldy, B. D., Trimpop, R. M., \& Williams, S. (2002). Occupational stress and health outcome among British and German managers. Journal Managerial Psychology, 17(6), 491-505.

Kline, R. B. (2005). Principles and practice of structural equation modeling. New York: The Guilford Press.

Kobasa, S. C., Maddi. S. R., \& Kahn, S. (1982). Hardiness and health: A prospective study. Journal of Personality and Social Psychology, 42(1), 168-177.

Kreitner, R., \& Kinicki, A. (2008). Organizational behavior (8th ed.). Boston: McGraw-Hill Irwin.

Larsman, P., Thorn, S., Sogaard, K., Sandsjo, L., Sjogaard, G., \& Kadefors, R. (2009). Work related perceived stress and muscle activity during standardized computer work among female computer users. Work, 32, 189-199.

Lazarus, R. S. (1999). Stress and emotion: A new synthesis. New York: Springer Publishing Company, Inc..

Lee, V., \& Henderson, M. (1996). Occupational stress and organizational commitment in nurse administrators. Journal of Nursing Administration, 26(5), 21-28.

Leung, T. W., Siu, O. L. \& Spector, P. E. (2000). Faculty stressors, job satisfaction, and psychological distress among university teachers in Hong Kong: The role of locus of control. International Journal of Stress Management, 7(2), 121-138.

Locke, E. A. (1976). The nature and causes of job satisfaction. In M. D. Dunnette (Eds.), Handbook of industrial and organizational psychology (pp. 1297-1349). Chicago: John Wiley \& Sons.

Lu, L., Kao, S. H., Cooper, C. L., \& Spector, P. E. (2000). Managerial stress: Locus of control, and job strain in Taiwan and UK: A comparative study. International Journal of Stress Management, 7(3), 209-226.

Lu, C. Q., Siu, O. L., \& Cooper, C. L. (2005). Managers' occupational stress in China: The role of self efficacy. Personality and Individual Differences, 38, 569-578.

Lu, L., Tseng, H. J., \& Cooper, C. L. (1999). Managerial stress, job satisfaction and health in Taiwan. Stress Medicine, 15 , 53-64.

MacDonald, G. (2006). What is mental health? In M. Cattan, \& S. Tilford (Eds.), Mental health promotion: A life span approach (pp. 8-32). Berkshire: Open University Press.

McDonald, R. P., \& Ho, M. (2002). Principles and practice in reporting structural equation analysis. Psychological Methods, 7, 64-82.

Meyer, J. P., \& Herscovitch, L. (2001). Commitment in the workplace toward a general model. Human Resource Management Review, 11, 299-326.

Ministry of Human Resources. (2009). Statistik pemburuhan dan sumber manausia. Retrieved from http://www. mohr.gov.my/pdf/A2009.pdf

Quick, J. C., \& Quick, J. D. (1984). Organizational stress and preventive management. New York: McGraw-Hill Book Company.

Schultz, D., \& Schultz, S. E. (2006). Psychology and work (9th ed.). Sydney: Pearson Prentice Hall.

Schwartz, J. (2004, September 5). Always on the job, employees pay with health. The New York Times. Retrieved from http://www.nytimes.com/2004/09/05/health/05stress.html 
Siu, O. L. (2002). Occupational stressors and well-being among Chinese employees: The role of organizational commitment. Applied Psychology: An International Review, 51(4), 527-544.

Siu, O. L., Cooper, C. L., \& Donald, I. (1997). Occupational stress, job satisfaction and mental health among employees of an acquired TV company in Hong Kong. Stress Medicine, 13, 99-107.

Siu, O. L., Lu, C. Q., \& Spector, P. E. (2007). Employee’ well-being in greater China: The direct and moderating effects of general self efficacy. Applied Psychology: An International Review, 56(2), 288-301.

Siu, O. L., Lu, L., \& Cooper, C. L. (1999). Managerial stress in Hong Kong and Taiwan: A comparative study. Journal of Managerial Psychology, 14(1), 6-25.

Siu, O. L., Spector, P. L., Cooper, C. L., \& Lu, C. Q. (2005). Work stress, self-efficacy, Chinese work values, and work well-being in Hong Kong and Beijing. International Journal of Stress Management, 12(3), 274-288.

Siu, O. L., Spector, P. L., Cooper, C. L., Lu, C. Q., \& Yu, S. (2002). Managerial stress in great China: The direct and moderator effect s of coping strategies and work locus of control. Applied Psychology: An international Review, 51(2), 608-632.

Spector, P. E., Cooper, C. L., \& Anguilar-Vafaie, M. (2002). A comparative study of perceived job stressor sources and job strain in American and Iranian managers. Applied Psychology, 51(30), 446-557.

Storseth, F. (2006). Changes at work and employee reactions: Organizational elements, job insecurity, and short-term as predictors for employee health and safety. Scandinavian Journal of Psychology, 47, 541-550.

Stranks, J. (2005). Stress at work: Management and prevention. Boston: Elsevier Butterworth Heinemann.

Sulsky, L., \& Smith, C. (2005). Work stress. California: Thomson Wadsworth.

Williams, S. (2000). Pressure management indicator. North Yorkshire: Resource system.

Williams, S., \& Cooper, C. L. (1998). Measuring occupational stress: Development of the pressure management indicator. Journal of Occupational Health Psychology, 3(4), 306-321.

Williams, S., \& Cooper, L. (2002). Managing workplace stress. West Sussex: John Wiley \& Sons, Ltd..

Yousef, D. A. (2002). Job satisfaction as a mediator of the relationship between role stressors and organizational commitment: A study from an Arabic cultural perspective. Journal of Managerial Psychology, 17(4), 250-266. 